\title{
Assesment of Mediastinoscopy Surgery Results in Patients with Mediastinal Tumor Reffered to Besat Hospital from 2014 to 2019 in Hamadan, Iran
}

\author{
Hamidreza Khorshidi ${ }^{1}$, Masoud Tarbiat ${ }^{2}$, Abbas Moradi ${ }^{3}$, Babak Karimi ${ }^{4, *}$ \\ ${ }^{1}$ Associate Professor, Department of General Surgery, School of Medicine, Hamadan University of Medical Sciences, \\ Hamadan, Iran \\ ${ }^{2}$ Associate Professor, Department of Anesthesiology, School of Medicine, Hamadan University of Medical Sciences, \\ Hamadan, Iran \\ ${ }^{3}$ Instructor, Department of Community Medicine, School of Medicine, Hamadan University of Medical Sciences, Hamadan, \\ Iran \\ ${ }^{4}$ Resident, Department of General Surgery, School of Medicine, Hamadan University of Medical Sciences, Hamadan, Iran \\ * Corresponding Author: Babak Karimi, Department of General Surgery, School of Medicine, Hamadan University of \\ Medical Sciences, Hamadan, Iran.Email: babakkarimimd@gmail.com
}

Received: 14.05 .2020

Accepted: 13.08 .2020

\section{How to Cite this Article:} Khorshidi H, Tarbiat M, Moradi A, Karimi B. Assesment of Mediastinoscopy Surgery Results in Patients with Mediastinal Tumor Reffered to Besat Hospital from 2014 to 2019 in Hamadan, Iran. Avicenna J Clin Med. 2020; 27(2): 94-99. DOI: 10.29252 ajcm.27.2.94

\section{Abstract}

Background and Objective: One of the important steps in continuing the treatment of patients with mediastinal masses is the definitive diagnosis using tissue sampling of the lesion within the mediastinum. One of the methods used for this purpose is mediastinoscopy. In this regard, this study aimed to determine the results of mediastinoscopic surgery in patients with a mediastinal mass.

Materials and Methods: This descriptive study evaluated the medical files of all patients who underwent mediastinoscopic surgery in Besat Hospital, Hamadan, Iran, from 2014 to 2019.

Results: This study was conducted on 19 patients with a mean age of 50.84 years. The majority of the participants were male $(n=11)$. The mass was located in the anterior mediastinum in most of the patients $(n=16)$, and in three cases, it was in the median mediastinum. Histopathological results showed inflammation $(n=4)$, small cell carcinoma $(n=3)$, lymphoma $(n=2)$, squamous cell carcinoma $(n=2)$, metastasis $(n=2)$, adenocarcinoma $(n=1)$, hydatid cyst $(n=1)$, tuberculosis $(n=1)$, sarcoidosis $(n=1)$, anthracosis $(n=1)$, and nonspecific $(\mathrm{n}=1)$ in descending order.

Conclusion: In general, there are similarities between the results of this study and those of other studies in terms of age, gender, place of involvement in the mediastinum, and surgical complications. On the other hand, there are differences between this study and other studies regarding the pathology results. It seems that the frequency of malignant masses in our study is higher than that in other studies.

Keywords: Mediastinal Neoplasms, Mediastinoscopy, Thoracic Surgery 
do: $10.29252 /$ ajcm.27.2.94

\title{
بررسى نتايج عمل جراحى مدياستينوسكويى در بيماران با توده مدياستن مراجعه كننده

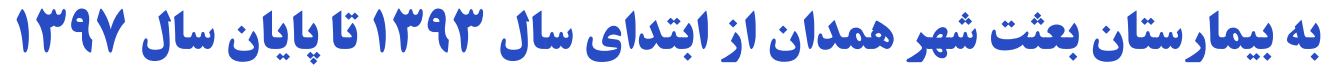

\author{
حميدرضا خورشيدى'، مسعود تربيت '، عباس مرادى '، بابك كريمى

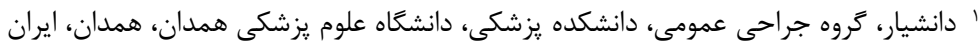

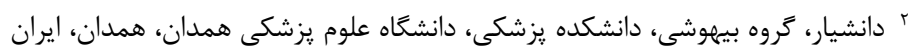

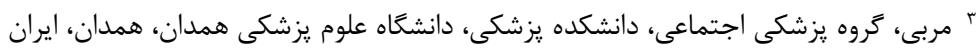

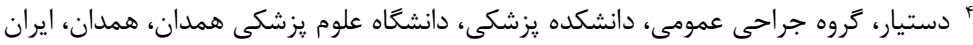
* نويسنده مسئول: بابك كريمى، كروه جراحى عمومى، دانشكده يزشكى، دانشكاه علوم بزشكى همدان، همدان، ايران. ايميل: babakkarimimd@gmail.com

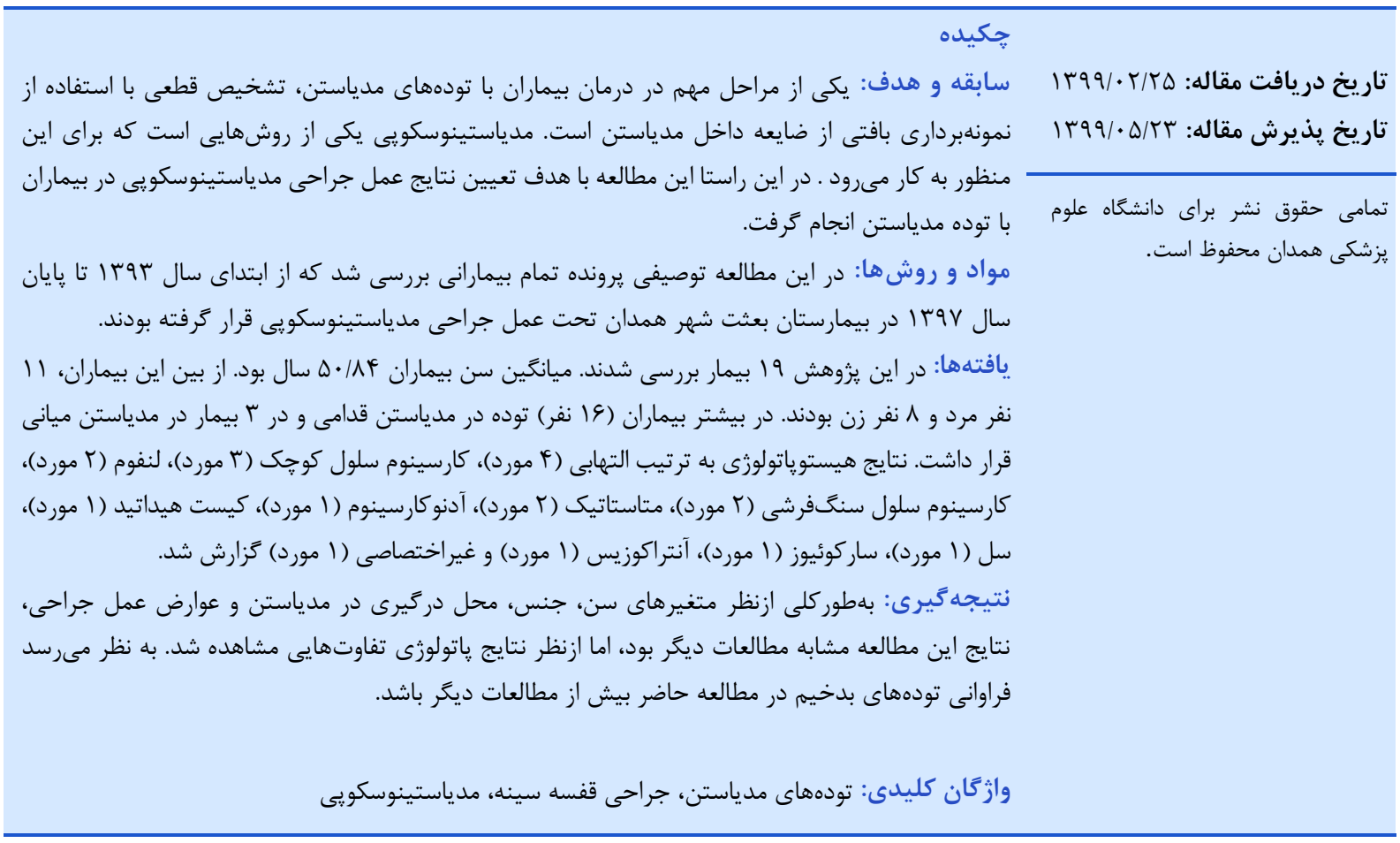

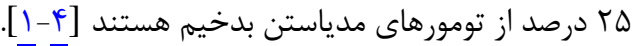

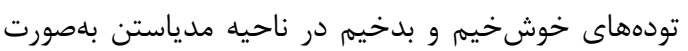

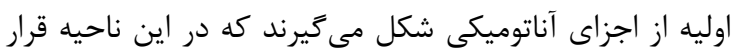

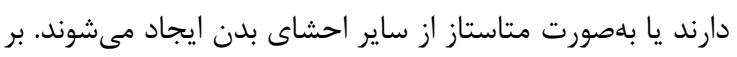
اساس آخرين مطالعات

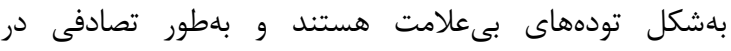

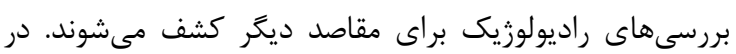

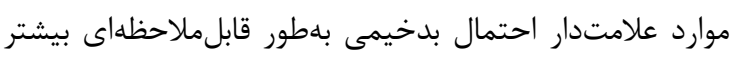

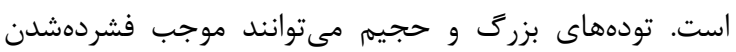
عناصر موجود در مدياستن بهخصوص ناى ندان و ايجاد سرفه،
مقلدمه مدياستينوم بهعنوان قسمت مركزى قفسه سينه براى

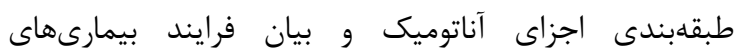
دركير كننده به بخشهاى قداى قدامى، ميانى و خلفى تقسيم مى شودي.

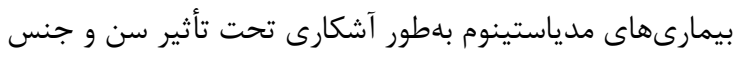

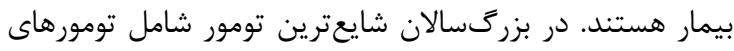

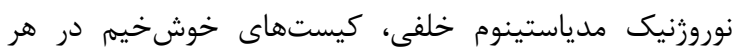
بخشى از مدياستن و تيموما در مدياستن قدامى است. در اطفئي

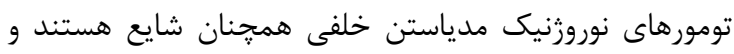

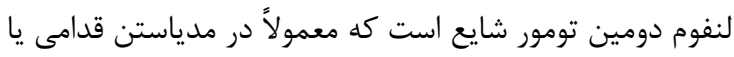

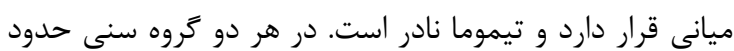


جدول ا: توزيع فراوانى گروههاى سنى بيماران با توده مدياستن كه تحت عمل جراحى مدياستينوسكويى قرار كرفتند

\begin{tabular}{|c|c|c|}
\hline درصد & تعداد & سن (سال) \\
\hline$\Delta / \Gamma$ & 1 & $1 .-r$. \\
\hline$\Delta / \Gamma$ & 1 & $r 1-r$. \\
\hline $1 \cdot 10$ & $r$ & $r l-p$. \\
\hline$r 1 / \Delta$ & 9 & $P_{1}-\Delta$. \\
\hline re/r & $\Delta$ & $\Delta 1-q$. \\
\hline$\Delta / r$ & 1 & s) $-V$. \\
\hline $10 / \Lambda$ & r & $v 1-\Lambda$. \\
\hline $1 \cdots$ & 19 & جمع \\
\hline
\end{tabular}

بيماران براى بررسى بيشتر و نمونهبردارى از توده مدياستن به فوق تخصص جراحى توراكس ارجاع شده بودند.

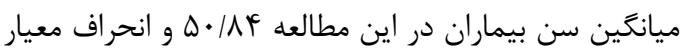
ف 19VV فراوانى افراد ازنظر كروههاى سنى در جدول آنس آورده شده است.

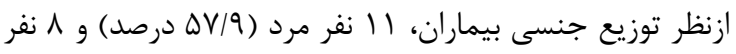

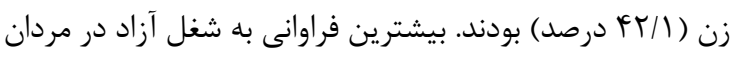

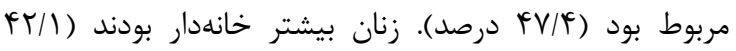

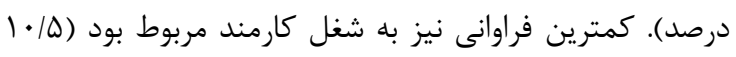

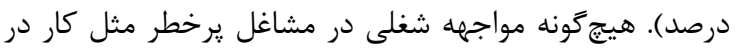

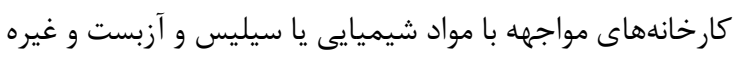
ذكر نشده بود.

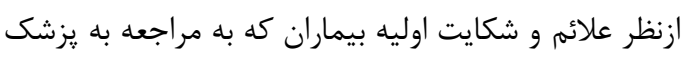

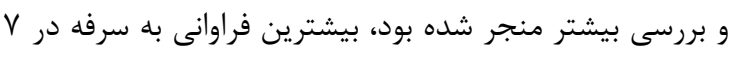

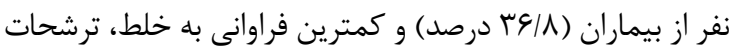

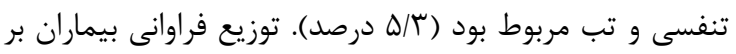

حسب علائم و شكايات اوليه در جدول r آورده شده است.

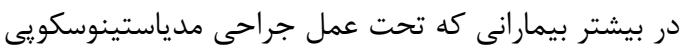

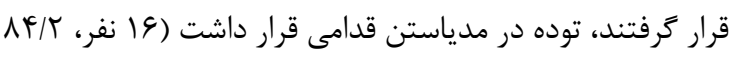

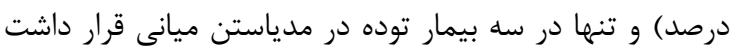

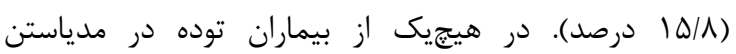

جدول r: توزيع فراوانى علائم اوليه بيماران با توده مدياستن كه تحت عمل جراحى مدياستينوسكويى قرار كرفتند

\begin{tabular}{|c|c|c|}
\hline درصد & ت عداد & علائم اوليه \\
\hline 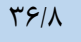 & V & سرفه \\
\hline$r 1 / \Delta$ & 4 & تنكى نفس \\
\hline $1 \cdot 10$ & r & درد قفسه سينه \\
\hline $1 \cdot 10$ & $r$ & كاهش وزن \\
\hline$\Delta / \Gamma$ & 1 & دفع خلط \\
\hline$\Delta / \Gamma$ & 1 & تب \\
\hline $1 \cdots$ & 19 & جمع \\
\hline
\end{tabular}

تنكَىنفس يا استريدور شوند؛ گَاهى نيز با دركيرى عصب راجعه

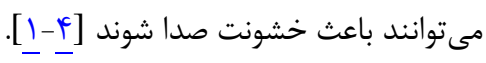

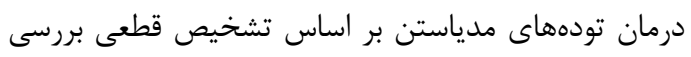

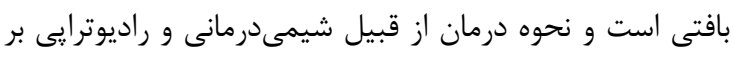

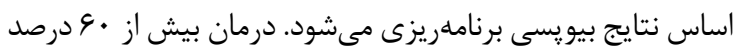

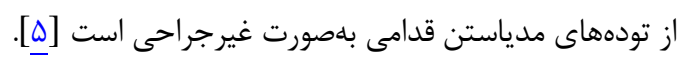
امروزه بيشتر از روشهاى جراحى كمتر تهاجمى استقبال

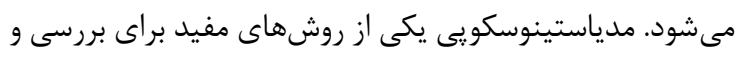

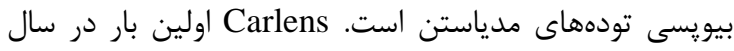

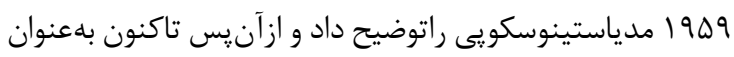

روش استاندارد بررسى تودههاى مدياستن به كار مىرود [ب].

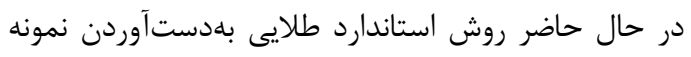
بافتى در ناحيه مدياستن، روش مدياستينوسكويى است. با اين

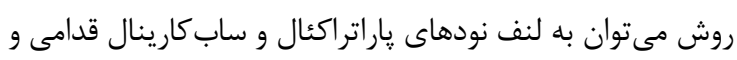

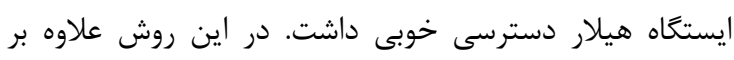

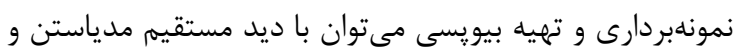

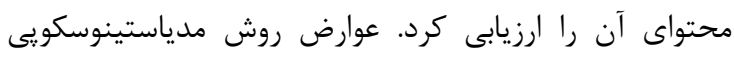

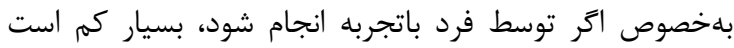

$[\varepsilon-11]$

با توجه به موارد ذكرشده اين مطالعه با هدف تعيين نتايج

عمل جراحى مدياستينوسكويى در بيماران با توده مدياستن

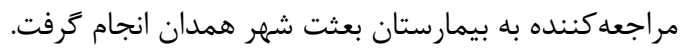

\section{مواد و روشها}

در اين مطالعه توصيفى يرونده تمام بيمارانى بررسى شد كه

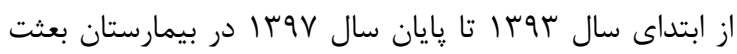
شهر همدان تحت عمل جراحى مدياستينوسكويى قرار گرفته

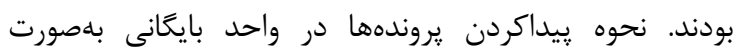

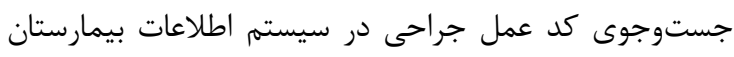
بود. اطلاعات لازم (HIS: Hospital Information System) در يرسشنامه طراحىشده ثبت و در صورت نقص در يرونده با

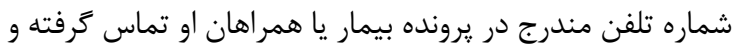

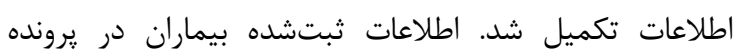

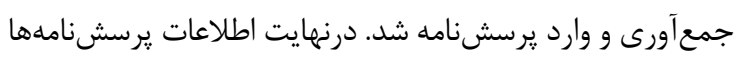

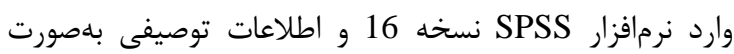
جدول و نمودار و درصد استخراج شد. ندرار

بافْته نا

در اين يزوهش يرونده 19 بيماران بررسى شد. تمام بيماران

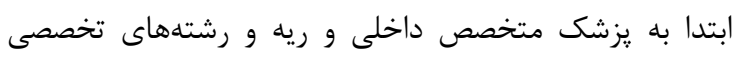

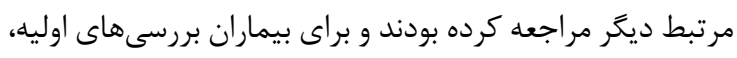
تصويربردارى و سىتىاسكن قفسه سينه انجام و توده مدياستن

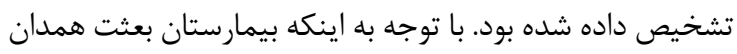

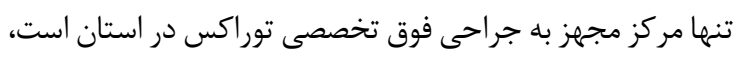


بررسىهاى تكميلى افراد در اين دسته شغلهاى متغير مثل

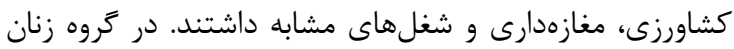

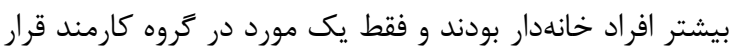

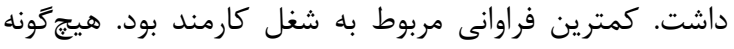

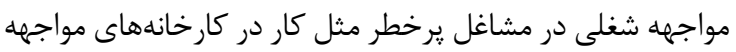

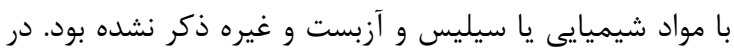

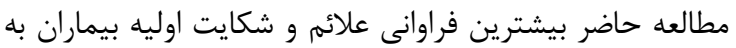

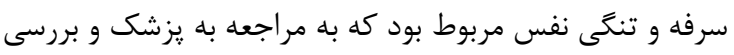

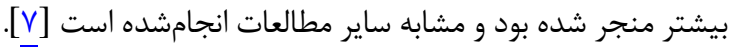

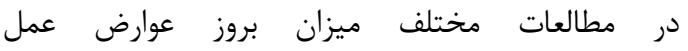

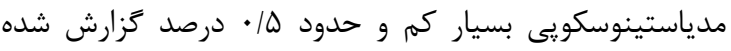

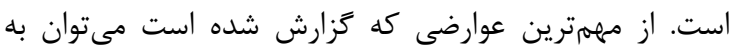

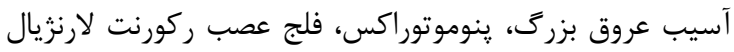

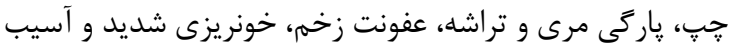

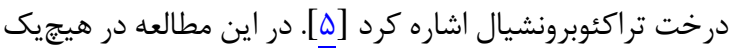

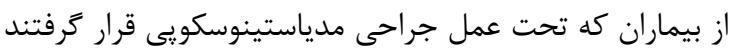

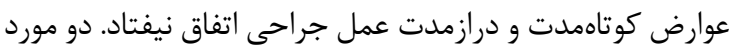

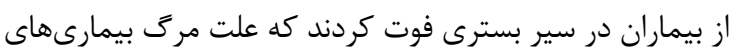

زمينهاى قلبى عروقى و كانسر ريه بِيشرفته ذكر شده است

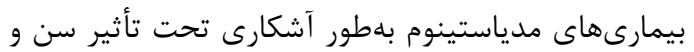
جنس بيمار هستند. طبق منابع، در بزركسالان شايعترين

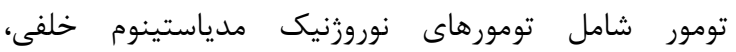
كيستهاى خوشخيم در هر بخشى از مدياستن و تيموما در در مدياستن قدامى است. در اطفال تومورهاى نورورثنيك مدين مدياستن

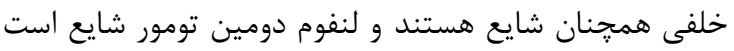

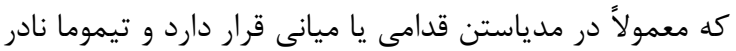

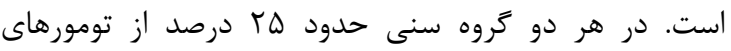
مدياستن بدخيم هستند [ب-1-1]. در مطالعه حاضر ميزان كلى تودههاى بدخيم

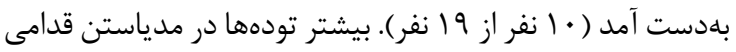

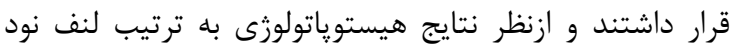

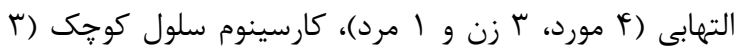

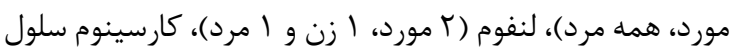

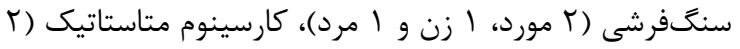

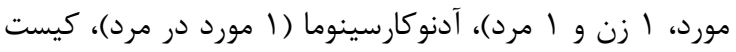

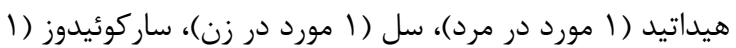

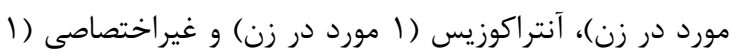

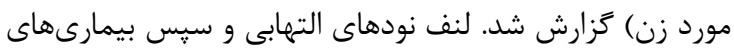

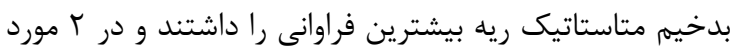

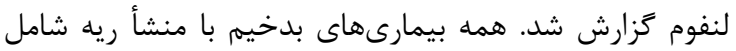

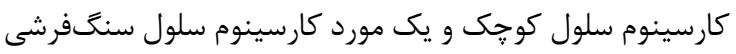

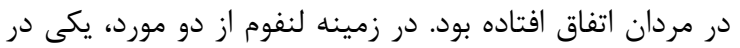

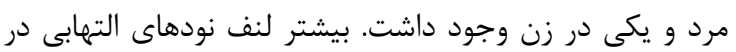

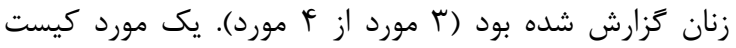

جدول با: توزيع فراوانى نتايج هيستوياتولوزى بيماران با توده

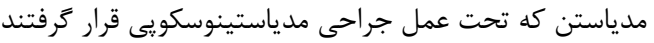

\begin{tabular}{|c|c|c|}
\hline درصد & تعداد & نتيجه باتولوزى \\
\hline$r M / 1$ & f & التهابى \\
\hline $\mid \Delta / \Lambda$ & r & كارسينوم سلول كوجك \\
\hline $1 \cdot 10$ & r & 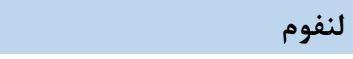 \\
\hline $1 \cdot 10$ & r & كارسينوم سلول سنَفرشى \\
\hline $1 \cdot 10$ & r & متاستاتيك \\
\hline$\Delta / \Gamma$ & 1 & آدنوكارسينوما \\
\hline$\Delta / \Gamma$ & 1 & كيست هيداتيد \\
\hline$\Delta / r$ & 1 & 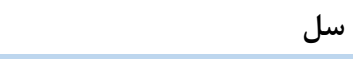 \\
\hline$\Delta / \pi$ & 1 & ساركوئيدوز \\
\hline$\Delta / \Gamma$ & 1 & آنتراكوزيس \\
\hline$\Delta / T$ & 1 & غير اختصاصى \\
\hline $1 \cdots$ & 19 & جمع \\
\hline
\end{tabular}

خلفى نبود. در هيجيك از بيماران كه تحت عمل جراحى

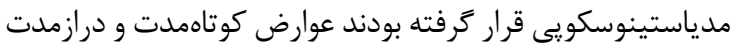
عمل جراحى اتفاق نيفتاده بود.

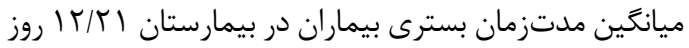

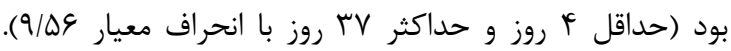

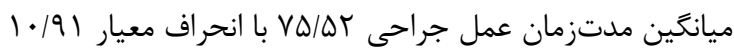

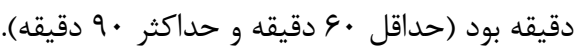
بر اساس نتايج پاتولوزى بيويسى توده مدياستن، شايعترين

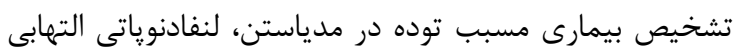

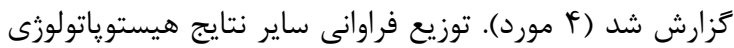
تودههاى بررسىشده در جدول ب آمده است.

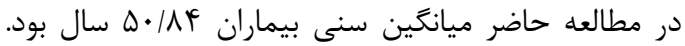

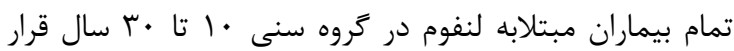

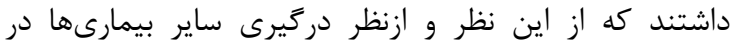

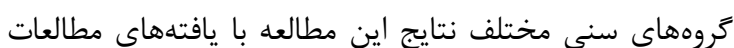
ديغر مشابه است [11-11- (1)] در بيشتر مطالعات تعداد مردان بررسى الإهده بيشتر از زنان

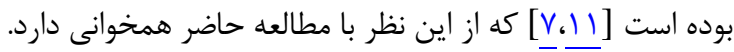
در مطالعه Onat و همكاران كه در كشور تركيه روى بيماران

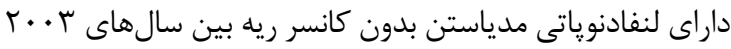

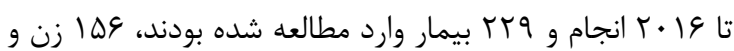

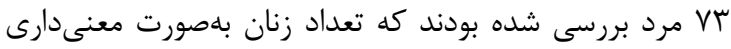

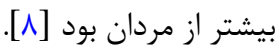

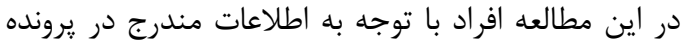

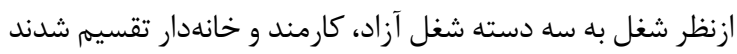

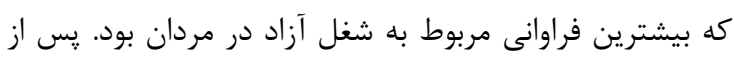




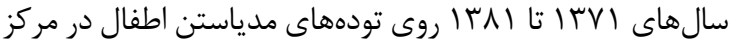

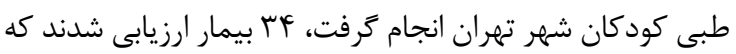

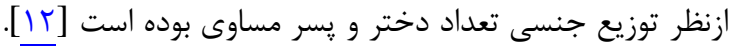

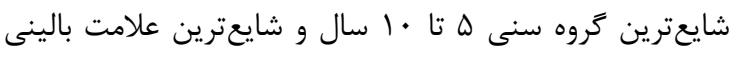

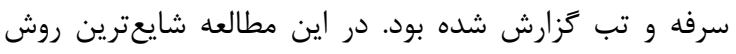

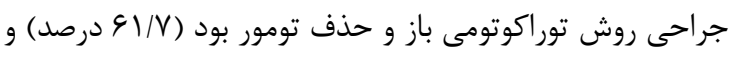

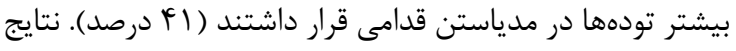

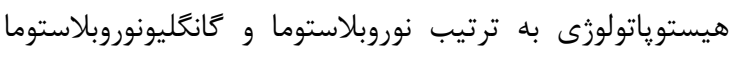

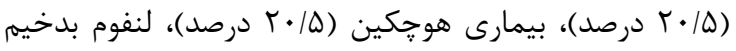

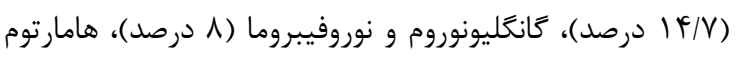

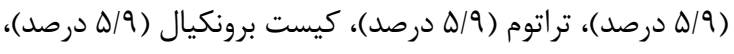

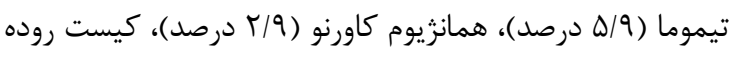

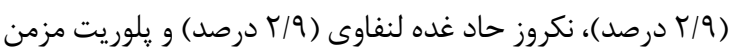

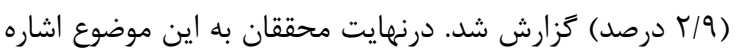

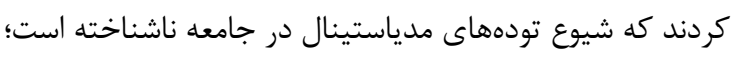

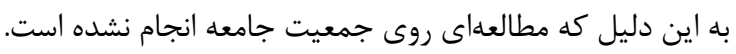

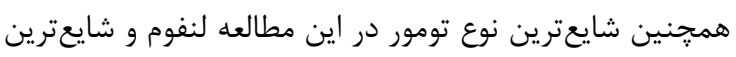
محل دركيرى مدياستن قدامى بوده كه مشابه ساير مطالعات كزارش شده است.

\section{نتيجه كيرى}

با توجه به يافته هاى مطالعه حاضر مى توان نتيجه كَرفت كه

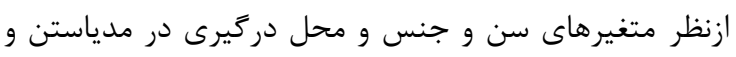

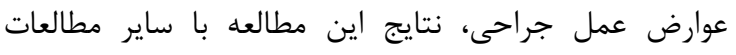

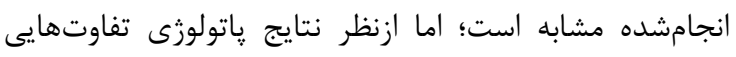

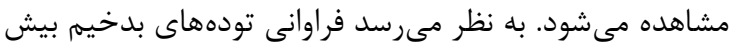

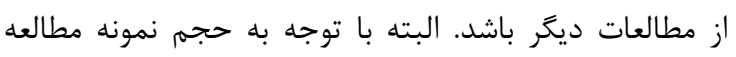

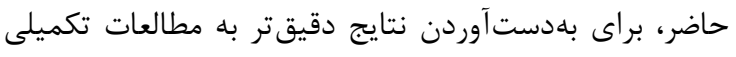

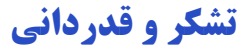

اين مقاله از پايان نامه دوره دكترى تخصصى جراحي

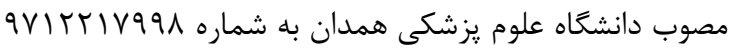

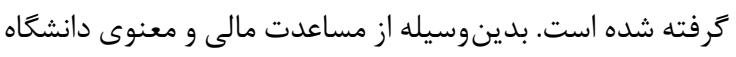

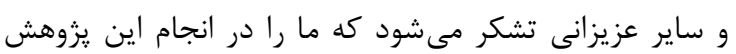

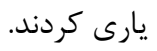

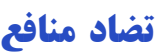

هيجَّونه تعارضى بين نتايج مطالعه و منافع نويسندكان

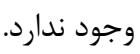

\section{ملاحظات اخلاقى}

اين مطالعه از كميته اخلاق دانشكاه علوم يزشكى همدان با بإسات شناسه IR.UMSHA.REC.1397.352 تأييديه دارد.
هيداتيد در مرد q4 ساله وجود داشت.

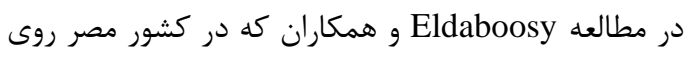

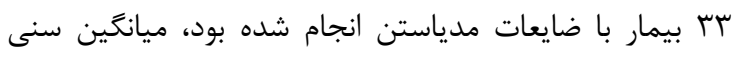

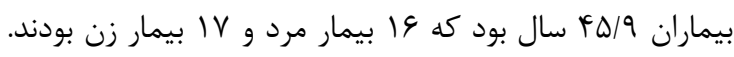

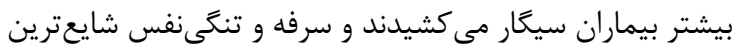

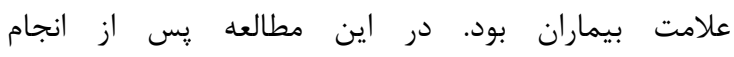

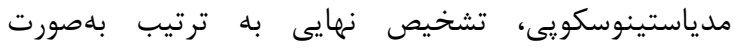

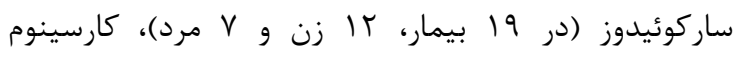

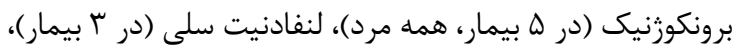

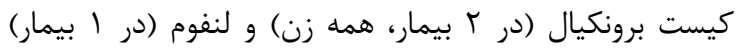

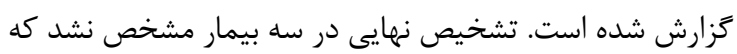

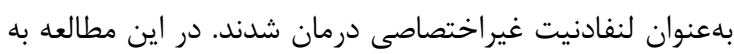

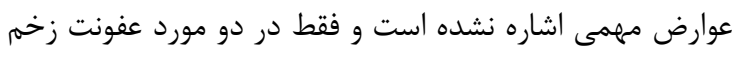

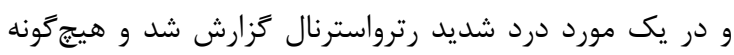

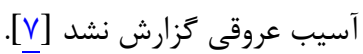

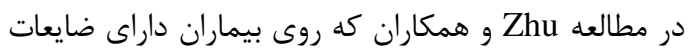

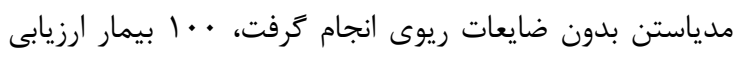

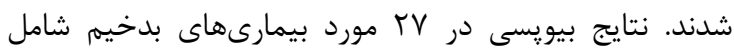

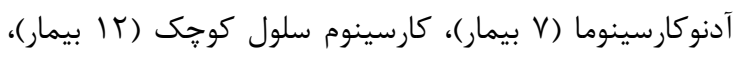

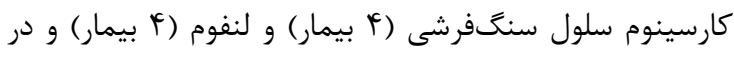

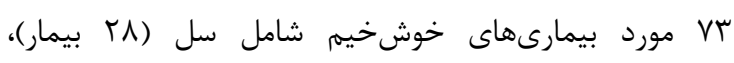

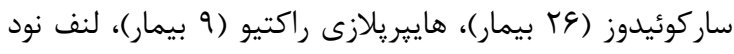

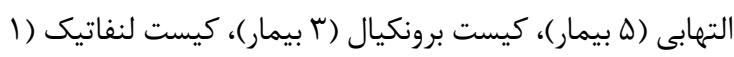

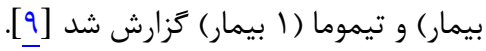

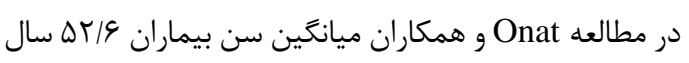

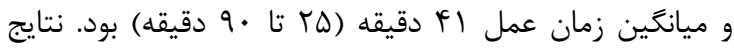

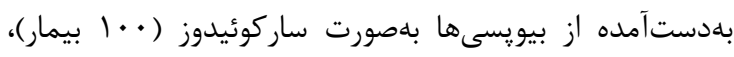

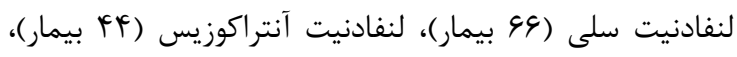

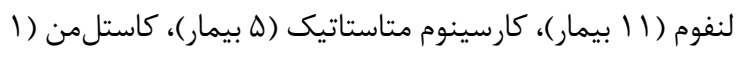

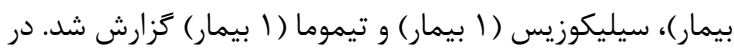

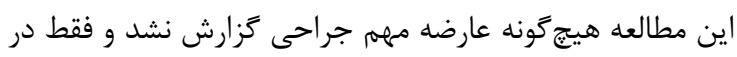

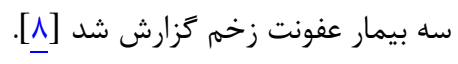

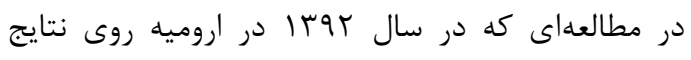

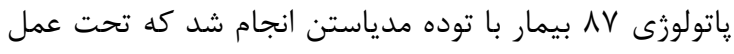

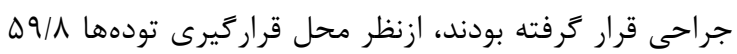

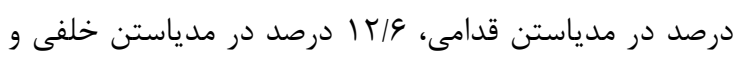

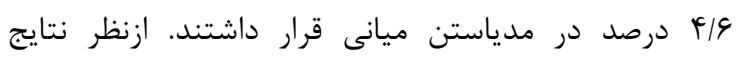

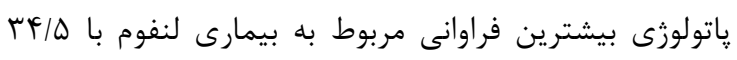

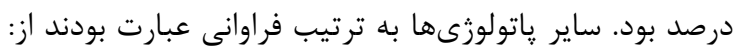

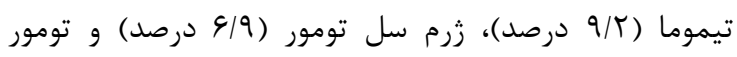

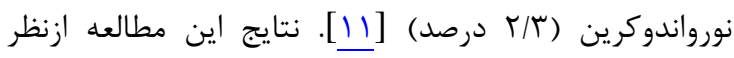

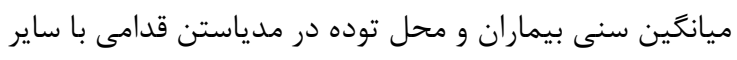
مطالعات يكسان بوده است. در مطالعه احمدى و همكاران كه در بازه زمانى • إساله بين 
(يزوهشكر اصلى): مسئول مكاتبات، تدوين :يرويوزال، بازنكرى

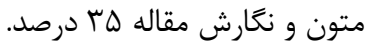

شمايت مالى

\section{REFERENCES}

1. Carter BW, Benveniste MF, Madan R, Godoy MC, de Groot PM, Truong MT, et al. ITMIG classification of mediastinal compartments and multidisciplinary approach to mediastinal masses. Radiographics. 2017;37(2):413-6. PMID: 28129068 DOI: $10.1148 / \mathrm{rg} .2017160095$

2. Billiar T, Andersen D, Hunter J, Brunicardi F, Dunn D, Pollock RE. Schwartz's principles of surgery. $10^{\text {th }}$ ed. New York: McGraw-Hill Professional; 2015. P. 670-80.

3. Carlens E. Mediastinoscopy: a method for inspection and tissue biopsy in the superior mediastinum. Dis Chest. 1959;36:34352. PMID: 13807712 DOI: $10.1378 /$ chest.36.4.343

4. Abdel Rahman MA. Standard cervical medias-tinoscopy in the diagnosis of mediastinal masses. J Egypt Nat Cancer Inst. 2002;15(3):253-8.

5. Yasufuku K, Pierre A, Darling G, de Perrot M, Waddell T, Johnston $\mathrm{M}$, et al. A prospective controlled trial of endobronchial ultrasound-guided transbronchial needle aspiration compared with mediastinoscopy for mediastinal lymph node staging of lung cancer. $J$ Thorac Cardiovasc Surg. 2011;142(6):1393-400. PMID: 21963329 DOI: 10.1016/j.jtcvs.2011.08.037

6. Chauhan A, Kapoor S, Ganguly M, Nath P. Cervical mediastinoscopy: re-evaluation of an old technique in era of new imaging technology. Indian J Chest Dis Allied Sci. 2012;54(3):169-73. PMID: 23008924

7. Eldaboosy SA, Zeinnhom RA, Kanany H, Nour MO. The value of cervical mediastinoscopy in the diagnosis of mediastinal lesions. Egypt $J$ Chest Dis Tuberculos. 2015;64(3):755-60. DOI: 10.1016/j.ejcdt.2015.03.030
8. Onat S, Ates G, Avc A, Yıldız T, Birak A, Akgul Ozmen C, et al. The role of mediastinoscopy in the diagnosis of nonlung cancer diseases. Ther Clin Risk Manag. 2017;13:939-43. PMID: 28794637 DOI: 10.2147/TCRM.S144393

9. Zhu F, Ma DC, Xu N, Xu XQ, Lv LP, Tang L, et al. Diagnostic efficiency of video-assisted mediastinoscopy and endobronchial ultrasound-guided transbronchial needle aspiration for mediastinal lymphadenectasis without pulmonary abnormalities. Med Sci Monit. 2017;23:3064-70. PMID: 28642455 DOI: 10.12659/msm.900968

10. Sayar A, Çitak N, Büyükkale S, Metin M, Kök A, Çelikten A, et al. The incidence of hoarseness after mediastinoscopy and outcome of video-assisted versus conventional mediastinoscopy in lung cancer staging. Acta Chir Belg. 2016;116(1):23-9. PMID: 27385137 DOI: 10.1080/000 15458.2015.1136483

11. Valizadeh N, Farrokhi F, Mehdiughli M, Eishi Oskuie A, Oshnouei S, Noroozinia F. Etiologic assessment of mediastinal masses in patients of Emam Khomeini Hospital in Urmia, Iran. J Urmia Univ Med Sci. 2014; 24(12):1036-9. [Persian]

12. Ahmadi J, Kalantari M, Mehrabi V, Nahvi H. A review of mediastinal tumors in children. Tehran Univ Med J. 2004;62(4):345-50. [Persian]

13. Hammoud ZT, Anderson RC, Meyers BF, Guthrie TJ, Roper $\mathrm{CL}$, Cooper JD, et al. The current role of mediastinoscopy in the evaluation of thoracic disease. J Thorac Cardiovasc Surg. 1999;118(5):894-9. PMID: 10534695 DOI: 10.1016/s00225223(99)70059-0 